\title{
Perceptual adjustment to time-compressed speech: A cross-linguistic study
}

\author{
CHRISTOPHE PALLIER \\ Universitat de Barcelona, Barcelona, Spain, \\ and Max Planck Institute for Psycholinguistics, Nijmegen, The Netherlands \\ NURIA SEBASTIAN-GALLÉS \\ Universitat de Barcelona, Barcelona, Spain
}

and

\author{
EMMANUEL DUPOUX, ANNE CHRISTOPHE, and JACQUES MEHLER \\ Laboratoire de Sciences Cognitives et Psycholinguistique, EHESS-CNRS, Paris, France
}

\begin{abstract}
Previous research has shown that, when hearers listen to artificially speeded speech, their performance improves over the course of 10-15 sentences, as if their perceptual system was "adapting" to these fast rates of speech. In this paper, we further investigate the mechanisms that are responsible for such effects. In Experiment 1, we report that, for bilingual speakers of Catalan and Spanish, exposure to compressed sentences in either language improves performance on sentences in the other language. Experiment 2 reports that Catalan/Spanish transfer of performance occurs even in monolingual speakers of Spanish who do not understand Catalan. In Experiment 3, we study another pair of languagesnamely, English and French-and report no transfer of adaptation between these two languages for English-French bilinguals. Experiment 4, with monolingual English speakers, assesses transfer of adaptation from French, Dutch, and English toward English. Here we find that there is no adaptation from French and intermediate adaptation from Dutch. We discuss the locus of the adaptation to compressed speech and relate our findings to other cross-linguistic studies in speech perception.
\end{abstract}

Speakers can utter a sentence while screaming or while whispering, with a stuffy nose or with lots of noise in the background, and under many other conditions that could be thought to affect utterance intelligibility. Yet the striking fact is that, despite this variability, intelligibility generally remains very good.

The persistence of intelligibility despite great changes in background noise, talker's voice, speech rate, dialect, and so forth has to be part of any reasonable account of speech perception. How is it that speech perception remains so amazingly accurate under these changing circumstances? Possibly the answer lies with the listener's processing apparatus, which has been devised to compensate for the input's instability. When listening conditions are

This research was supported by grants from the Human Frontier Science Program, the Human Capital Program of the EEC, the FrancoSpanish Exchange Program for 1993-1995, and the Fyssen Foundation. The first version of this paper was written while Christophe Pallier was a postdoc researcher at the Rutgers Center for Cognitive Science, New Brunswick, NJ. We thank Peter Golato for help in data gathering, William Marslen-Wilson and Suzanne Howard at the Center for Speech and Language at Birkbeck College, and John Morton at the Cognitive Development Unit, MRC, for letting us use their facilities to test English subjects (Experiment 4). Correspondence concerning this article should be addressed to C. Pallier, Laboratoire de Sciences Cognitives et Psycholinguistique, 54 Bd Raspail, 75006 Paris, France (e-mail: pallier@1scp.ehess.fr).

—Accepted by previous editor, Geoffrey $R$. Loftus not too degraded, the compensation seems almost instantaneous and effortless (see J. L. Miller, 1981, for a review of adaptation to changes in speech rate). Under more inordinate conditions, such as listening to a heavy foreign accent in a noisy conference room, a larger time frame is required for adaptation to be complete (for adaptation to synthetic speech, see Schwab, Nusbaum, \& Pisoni, 1985). The purpose of the present study is to expand our understanding of such compensation processes and to raise questions about speech perception from that perspective.

Past studies have used artificially compressed speech in order to quantify the way in which the speech processing system deals with variations in speech rate. Predictably, these studies have found that intelligibility decreases as compression rate increases (de Haan, 1982; Foulke \& Sticht, 1969; Heiman, Leo, Leighbody, \& Bowler, 1986; Schmitt, Moore, \& Lass, 1986). Likewise, over the course of exposure to such signals, subjects' performance tends to improve (Mehler et al., 1993; Voor \& J. M. Miller, 1965). After 10-15 sentences, performance reaches a plateau.

To explain this improvement in performance, several mechanisms can be advanced, ranging from low-level adjustments in the processing of acoustic properties to the use of ad hoc high-level strategies that improve the integration of information in memory systems. Our experiments investigate whether these adjustments involve the systems that map the acoustic information onto the proper 
lexical representations. If the resuits of these investigations reveal that adapting to compressed speech involves these systems, studying this adaptation is bound to help us understand speech perception at large.

Recent research that compares speech perception across varied linguistic settings indicates that speakers of different languages rely on processes that are specific to their maternal languages. Mehler, Dommergues, Frauenfelder, and Segui (1981) and Cutler, Mehler, Norris, and Segui (1983) have shown that French and English subjects behave in conflicting ways when they have to find a string of phonemes that coincides with the first syllable of a word. Such observations have led these authors to conclude that the specific phonological properties of each one of the languages induce the use of different properties to map sounds to meaning. In other words, speakers of French - a language with clearly marked syllabic structures and fixed accents - use syllables to initiate lexical processes, whereas speakers of English-a language with ambisyllabicity and contrastive stress - adopt a different strategy.

The above conclusions have been substantiated by research conducted in other languages with a wide variety of experimental procedures (Bradley, Sánchez-Casas, \& García-Albea, 1993; Cutler, Mehler, Norris, \& Segui, 1986, 1992; Otake, Hatano, Cutler, \& Mehler, 1993; Pallier, Sebastian-Gallés, Felguera, Christophe, \& Mehler, 1993; Sebastian-Gallés, Dupoux, Segui, \& Mehler, 1992; Zwitserlood, Schriefers, Lahiri, \& Donselaar, 1993). From these studies, it emerges that the nature of accent, the number of vowels, the extent to which the language relies on vowel reduction, and so forth are all factors that influence how the acoustic signal is exploited in order to identify lexical candidates. If these conclusions are correct, the perceptual adjustments to compressed speech in a given language might be of little or no use when another language is presented under similar conditions, unless the languages are treated alike at some early processing stage. Accordingly, the study of adaptation across languages would help us understand the way in which acoustic information is processed by speakers in general and how language diversity may influence such processes.

Before becoming entangled in such issues, however, it is judicious to establish the possible contributions of the above-mentioned levels to habituation to fast speech. If most of the adaptation is due either to very low level acoustic mechanisms or to very late high-level postlexical procedures, the interest in using this experimental procedure would be rather limited. On the basis of various observations, however, we can dismiss the belief that low-level acoustic processing plays an extensive role in this adaptation. For instance, Dupoux and Green (1997) have shown that, once subjects have adapted to compressed speech, their performance remains unaffected by a change in speaker (male to female). This result suggests that, although adaptation is specific to compressed speech, it occurs at a level sufficiently abstract that talker- specific acoustic information only plays a minor role. What about the view that it is very late, high-level processes that are responsible for most, if not all, of the observed adaptation effects? Little data can be advanced to respond to this question. However, there are easy experiments that could provide us with a clear answer to that question. For instance, if the adaptation takes place at a late (postlexical) level, it should be driven by lexical or semantic variables; accordingly, one might expect that speakers would show transfer only after they adapted to a language they understood. Indeed, it would follow that adaptation would be impossible to a language that subjects cannot understand.

The research we report here has two main goals: first, to establish whether high-level processes (lexical and semantic) are essential for explaining adaptation to compressed speech; second, to evaluate whether phonological information plays a role in the adaptation to compressed speech. To attain these goals, we have carried out four experiments, through which we explore how monolingual and bilingual speakers adjust to compressed speech in different languages. Specifically, two language pairs have been chosen: Catalan-Spanish and French-English. The choice of the first pair is justified for two reasons: first, the fact that these two languages have comparable phonological properties and speakers of these languages seem to rely on similar speech perception routines (SebastianGallés et al., 1992); and second, our easy access to a large Catalan-Spanish bilingual community. The second pair, French-English, was selected because these two languages rely on different representations (Cutler et al., 1986, 1992) - or, at least, on representations that are much more distant from one another than those of Catalan and Spanish-and also because of the ease of finding a bilingual population.

If semantic processing plays a major role in the adaptation to compressed speech, then bilinguals (both CatalanSpanish and French-English) ought to transfer the adaptation secured with one language onto the other one. In contrast, if phonological variables are a primary factor in determining adjustment, the phonological proximity of the languages will be a determinant factor. If this is the case, both bilingual and monolingual subjects should show transfer between Spanish and Catalan, whereas neither bilingual nor monolingual French-English subjects should show transfer.

\section{GENERAL METHOD}

In the experiments reported below, we presented the subjects with a set of habituation sentences in one language ( 8 or 10 sentences), followed by a set of compressed test sentences in the same language or in another language. In both the habituation and test phases, after hearing each sentence, the subjects were asked to write down all they could recall, and these responses were scored in terms of the number of recalled syllables. (In a previous study, we found that scoring in terms of words or syllables did not lead to contrasting results [Mehler et al., 1993] ). Using the number of recalled syl- 
lables instead of recalled words also allowed us to score the performance of listeners exposed to a foreign language. The dependent variable was the percentage of recalled syllables as a function of type of habituation, which is subjected to between-subjects and within-items comparisons. Because of the between-subjects design of the experiments, care was taken to make sure that the test sentences were presented under similar listening conditions for all of the groups. Moreover, the subjects in the different pairs of languages were taken from the same population and assigned randomly to one of the experimental groups.

The compression rate, which varied from study to study, was adjusted for each study so that initial performance was between $30 \%$ and $70 \%$ of syllables correctly recalled. This was done to avoid ceiling or floor effects. The materials were recorded and digitized at $16 \mathrm{kHz}$ ( 16 bits quantization) and compressed using the PSOLA algorithm (Charpentier \& Stella, 1986). The program operates by first labeling the signal at each consecutive pitch period. Unvoiced portions of speech are blindly labeled into chunks equal to the size of the mean pitch period. Next, adjacent pitch periods are averaged in the time domain according to a scheme that depends on the compression rate. The averaging window is slightly longer than the width of each pitch period, with vanishing smoothing functions on either side. The end result is a signal with fewer pitch periods than the original signal. For example, a signal compressed at a $50 \% \mathrm{com}$ pression rate will end up with only half the number of pitch periods as the original signal. However, since the information is averaged across adjacent pitch periods and not simply deleted, the signal retains many of the brief acoustic events, such as release bursts, that are important to phonetic perception.

\section{EXPERIMENT 1 Spanish-Catalan Bilinguals}

Spanish and Catalan are two Romance languages that have quite similar phonologies. They both are syllabletimed languages with lexical stress. Even though they differ in several phonological dimensions (for instance, Catalan is a language with vowel reduction, whereas Spanish is not), they seem to rely on similar processing strategies (Pallier et al., 1993; Sebastian-Gallés et al., 1992). All in all, it seems reasonable to conjecture that the procedures for mapping acoustic information onto lexical representations ought to be quite similar for the two languages. Consequently, if phonological representations participate in the process of adaptation to compressed speech, this adaptation ought to transfer from one language to the other.

\section{Method}

Materials and Procedure. Fifteen Spanish sentences and 15 Catalan sentences, matched for meaning and length in syllables, were selected (see the Appendix). Ten sentences in each language (matched) were chosen as habituation sentences; the other 5 were chosen as test sentences. All sentences were then recorded from two female bilingual speakers of Spanish and Catalan, digitized, and compressed at $38 \%$ of their original duration.

There were six experimental groups. Three groups had test sentences in Catalan, and three others had test sentences in Spanish. In the different language condition, two groups of subjects received the habituation sentences in a different language from that in the test sentences. In the same language condition, two other groups of subjects listened to test and habituation sentences in the same language but spoken by a different speaker. Finally, the control condi- tion consisted of two other groups of subjects who listened only to the experimental sentences.

The subjects were tested individually in a sound-attenuated room. Sentences were presented through a tape recorder (Tascam Porta One), binaurally over headphones.

Subjects. Forty-eight bilingual Catalan-Spanish subjects were assigned to each of the same language groups and another 48 subjects to each of the different language groups. Twenty-eight subjects were assigned to each one of the control groups. In all, 248 subjects were tested. All of the subjects were highly proficient in both Spanish and Catalan and spoke both languages daily with equal fluency. They were all first- and second-year undergraduate students at the University of Barcelona. They received course credits for their participation in the experiment.

\section{Results}

A global analysis of variance (ANOVA) with language of the test sentences (Spanish or Catalan) and experimental condition (same language, different language, and control) as between-subjects factors was performed. The two main effects were significant. The subjects were more accurate in reporting the experimental sentences in Spanish than in Catalan $[F(1,242)=39.7, p<.0001]$, and there are also differences between the three experimental groups $[F(2,242)=41, p<.0001]$. However, the interaction between the two factors was not significant $[F(2,242)=1.58$, $p=.21]$. Means for each experimental group are displayed in Table 1. Planned comparisons of means show that there are statistically significant differences between the three experimental conditions. The control groups differ from both the same language $[t(150)=10.36, p<.0001]$ and the different language groups $[t(150)=8.05, p<.0001]$. The same language and different language groups also differ significantly from each other $[t(190)=2.86, p<.005]$.

\section{Discussion}

Highly compressed speech in Catalan or in Spanish can be used by proficient bilingual speakers to improve their performance when they are exposed to one or to the other language. Moreover, once the subjects adapt to one of the languages, they benefit from such an adaptation when they are switched to the test sentences in the other language. Indeed, the performance of the different language group was significantly better than that of the control group. Nevertheless, the transfer was not perfect, since the same language and different language groups differ significantly from each other.

Table 1

Mean Percent Recalled Syllables (With Standard Errors)

From Compressed Spanish and Catalan Sentences for Catalan-Spanish Bilingual Subjects as a Function of Previous Habituation

\begin{tabular}{lllllll}
\hline & \multicolumn{2}{c}{$\begin{array}{c}\text { Spanish } \\
\text { Sentences }\end{array}$} & & & $\begin{array}{c}\text { Catalan } \\
\text { Sentences }\end{array}$ & \\
\cline { 2 - 3 } \multicolumn{1}{c}{ Habituation } & $M$ & $S E$ & & $M$ & $S E$ & Average \\
\hline None & 66 & 1.5 & & 57 & 2.1 & 61 \\
Same language & 91 & 1.1 & 78 & 1.3 & 85 \\
Different language & 83 & 1.8 & 76 & 1.6 & 80 \\
\hline
\end{tabular}


It is, however, difficult to attribute the cross-linguistic transfer exclusively to phonological factors. Indeed, the bilingual subjects were equally fluent in both languages, and they had an excellent understanding of the sentences in both languages. It could be, then, that adaptation to fast rates is taking place at the syntactic/semantic level (i.e., subjects who adapt are able to quickly derive a high-level representation under temporal pressure), in which case cross-linguistic transfer would occur whenever subjects understand the two languages at hand. The next experiment was designed to assess the possible contribution of semantic information to the adjustment processes.

\section{EXPERIMENT 2 Spanish Monolinguals}

In this experiment, monolingual Spanish subjects were tested with the same sentences as those in Experiment 1, with one difference: They always received the test sentences in Spanish. If the adjustment mechanism is mainly driven by semantic structures, no transfer from Catalan should be observed, given that monolingual subjects do not understand Catalan.

\section{Method}

Materials and Procedure. The same experimental procedure and materials as those in the previous experiment were employed. The three groups received the test sentences in Spanish; the different language group was habituated to Catalan and the same language group to Spanish, whereas the control group heard only the Spanish test sentences. The subjects were asked to write down the sentences even during the habituation phase. For the different language group, the subjects were asked to do a transcription, as best they could, of the Catalan habituation sentences.

The subjects were tested in a quiet room in groups of two, although they could not see each other. Sentences were presented over headphones with the same equipment as that in the previous experiment.

Subjects. The subjects were college students at a Madrid school who volunteered to take the experiment. None of them knew Catalan. Special care was taken in selecting subjects who had no significant previous exposure to Catalan (e.g., by spending summer holidays in Catalan-speaking regions). There were 12 subjects in each of the groups, for a total of 36 subjects.

\section{Results}

An ANOVA was performed on the mean percentage of correct syllables reported for the test sentences (see Table 2). The effect of experimental condition (same language vs. different language vs. control) was highly significant $[F(2,33)=22.9, p<.001]$. Comparisons of means showed that there were no differences between the same

Table 2

Mean Percent Recalled Syllables From Compressed Spanish Sentences for Monolingual Spanish Subjects as a Function of Previous Habituation

\begin{tabular}{lll}
\hline & \multicolumn{2}{c}{ Spanish Sentences } \\
\cline { 2 - 3 } Habituation & $M$ & $S E$ \\
\hline None & 76 & 3.3 \\
Same language & 86 & 2.7 \\
Different language & 85 & 3.4 \\
\hline
\end{tabular}

language and different language groups $(t<1)$, but that these two groups were different from the control one [different language vs. control, $t(21)=2.06, p=.05$; same language vs. control, $t(21)=2.37, p=.03$ ]

\section{Discussion}

The monolingual Spanish subjects who adapted with Catalan sentences performed better than the control subjects. The subjects in this experiment profited similarly from listening to Catalan or to Spanish during the habituation phase.

It is important to note that the monolingual Spanish subjects were unable to understand the compressed Catalan sentences presented during the habituation phase. The average number of correctly reported syllables was $15 \%$, and these mostly corresponded to function words that are very similar in the two languages. The bilingual subjects tested in Experiment 1 reported over $75 \%$ correct syllables on these same sentences. Yet, both bilinguals and monolinguals benefited equally from the presentation of Catalan when tested with Spanish (if anything, the monolinguals seemed to benefit more, since their performance for Catalan habituation was no different from that for Spanish habituation). This clearly indicates that understanding is not essential for adaptation to take place. Hence, the transfer of adaptation between Catalan and Spanish cannot be due to adjustments taking place at high levels of processing. It has to be at a shallow processing level, presumably before lexical access.

It could be that subjects adapt to fast signals, whether or not these signals are in their language and, perhaps, whether or not they are linguistic signals at all. There are reasons to doubt that such low-level effects might account for our findings. Indeed, this explanation should predict that any two pairs of languages would show adaptation. In fact, Altmann and Young (1993) failed to observe transfer from French to English or the reverse, for monolinguals of either of these languages. The finding that certain pairs of languages show transfer whereas others do not is important, because it would suggest that adaptation is relying not on raw acoustic properties but rather on linguistic (presumably phonological) ones. Languages that share many phonological properties might show more transfer than languages that are more phonologically distant. However, before going into these issues, one has to assess whether the failure of English-French transfer is real.

There is, unfortunately, one procedural difference between the Altmann and Young (1993) study and our Experiments 1 and 2: During the habituation phase, we required the subjects to write down what they heard, whereas this was not the case in the Altmann and Young study. Since the understanding of compressed speech in a foreign language is so difficult, subjects may simply fail to pay attention to the sentences in the habituation set and may wait for the test sentences in their native language.

The next experiment was designed as an attempt to replicate Altmann and Young's (1993) results with English- 
French bilingual subjects. An additional measure we adopted was that our subjects were required to write down both habituation and test stimuli.

\section{EXPERIMENT 3 French-English Bilinguals}

Speakers of English and speakers of French may rely on different properties to encode speech. Vowel reduction, an important property of English, is almost nonexistent in French. Syllables, in contrast, play a greater role in the representation of French than in that of English. These two languages are, thus, much more phonologically distant than are Spanish and Catalan.

In this experiment, bilingual French-English subjects were tested and, as in Experiments 1 and 2, were asked to write down as much as they could recall of the habituation and the test sentences. If the failure to obtain any transfer between French and English is due solely to a lack of attention during the habituation phase, transfer should be observed in Experiment 3. On the other hand, if the explanation of the results lies with differences in phonologically related processing, the pattern of results obtained by Altmann and Young (1993) should be replicated in Experiment 3.

\section{Method}

Materials and Procedure. Sixteen sentences in French were constructed and matched to 16 sentences in English; the sentences in English and French had the same number of words and syllables and were translations of one another. The 16 sentences in French were split into two groups, A and B, and the English sentences were also split into two corresponding groups, $A$ and $B$. Half of the subjects started with sentences in Group $A$ and switched to $B$ in the other language, whereas the other half started with sentences in Group $B$ and switched to $A$ in the other language. This resulted in four groups of subjects: A-French going to B-English, B-French going to A-English, A-English going to B-French, and B-English going to A-French. The subjects were tested in groups of five in a classroom, with the sentences played over two loudspeakers. After each sentence was played, the subjects were asked to write down all that they could recall. The sentences were recorded by a bilingual female speaker and were compressed with the PSOLA algorithm, as above. The sentences were compressed to $40 \%$ of their initial duration.

Subjects. Sixty-eight bilingual student subjects (17 in each group) were tested at their school on the outskirts of Paris. The school, the Lycee International, caters to students who are bilinguals and who want to pursue high school studies in both languages in parallel. The students were selected after consultation with their teachers and after an evaluation of their performances in each language. They were fluent in both languages, had no foreign accent in either, and

Table 3

Mean Percent Recalled Syllables (With Standard Error) From Compressed French and English Sentences for French-English Bilingual Subjects as a Function of Preceding Habituation

\begin{tabular}{lcccccc} 
& \multicolumn{2}{c}{$\begin{array}{c}\text { French } \\
\text { Sentences }\end{array}$} & & \multicolumn{2}{c}{$\begin{array}{c}\text { English } \\
\text { Sentences }\end{array}$} \\
\cline { 2 - 3 } \cline { 5 - 6 } Habituation & $M$ & $S E$ & & $M$ & $S E$ & $M$ \\
\hline None & 62.9 & 3.1 & & 21.6 & 1.7 & 42.2 \\
In other language & 58.1 & 3.3 & & 22.0 & 2.1 & 40.0 \\
\hline
\end{tabular}

had practiced both languages continuously since the age of three. They were 16 to 18 years old at the time of testing.

\section{Results}

In Table 3, we present the results for the subjects' performances on sentences before and after adaptation to the other language. The design allowed us to compare performances on exactly the same sentences before and after adaptation, although presented to different groups of subjects.

We conducted an ANOVA on the number of syllables correctly reported in the different conditions. A global analysis included the four groups as a between-subjects factor and change (before vs. after) as a within-subjects factor. None of the main factors introduced a significant effect. The only significant effect was an interaction between groups and change $[F(1,64)=287, p<.0001]$. This interaction was due to the fact that French sentences produced better recall rates than did English sentences. A $t$ test performed on the French sentences revealed no significant difference between before change and after change. Similarly, performance on English sentences was not significantly different before and after change.

\section{Discussion}

The pattern of results observed in this experiment shows that bilingual French-English subjects do not benefit from listening to sentences in English when they are tested in French or vice versa. Thus, we can conclude that understanding the language to which one is exposed is not sufficient for adaptation to compressed speech to extend to sentences in one's native language. This complements Experiment 2, which demonstrated that understanding was not necessary for adaptation to take place. Together, these results suggest that adaptation does not rely on lexical processes. The data are compatible, however, with the notion that adaptation occurs at a phonological level, one that involves processing strategies that are linked to one's native language. If this is true, we expect adaptation to transfer across languages that have similar phonological properties. Phonologically speaking, Dutch and English have much more in common than do French and English. For instance, both have been described as stress-timed languages, whereas French has been classified as a syllabletimed language (Abercrombie, 1967). Yet there are differences between English and Dutch-for example, with respect to the distinctive status of vowel length and the salience of retroflex consonants in Dutch. All the same, we predict that English monolinguals who are trained with compressed Dutch will perform better than they would if they were trained with French. Our next experiment was designed to evaluate this prediction.

\section{EXPERIMENT 4 Monolingual English Subjects}

This experiment contrasts the effectiveness of exposure to French, Dutch, or English, on the performance of native speakers of English. 


\section{Method}

Materials and Procedure. We first selected 5 English sentences, 18-19 syllables long, to be used as test items (see the Appendix). We then selected 10 sentences in Dutch, in French, and in English for use as habituation items. These sentences were selected from a multilingual corpus of sentences gathered at the LSCP by Thierry Nazzi. Thus, it was possible to equate the number of syllables and, approximately, the mean duration of the habituation sentences across languages (averages $=18$ syllables and $3.4 \mathrm{sec}$ ). In a given language, all habituation sentences were spoken by the same speaker. The 5 test sentences were also pronounced by a single speaker.

We compressed the test sentences to $40 \%$ of their original duration and the habituation sentences to $50 \%$. These rates were chosen on the basis of a pilot test, to avoid ceiling or floor performance. The compressed sentences were recorded on DAT tapes, in four lists: (1) one comprising only the five test sentences (no habituation condition); (2) one with 10 English habituation sentences, followed by the 5 English test sentences; (3) one with 10 French sentences, followed by the 5 English test sentences; and (4) one with 10 Dutch sentences, followed by the 5 English test sentences. Each sentence was preceded by a tone, followed by 2 sec of silence to allow the subjects to focus their attention. After each sentence, the subjects had $30 \mathrm{sec}$ to write down what they had heard. They were encouraged to write down as much as possible, even in the foreign language conditions; moreover, they were told that the last 5 sentences were in English. There were four groups of subjects, each assigned to one of the lists.

Subjects. Seventy-five English native speakers were tested at the Centre for Speech and Language and the Cognitive Development Unit in London. Eighteen were assigned to the Dutch habituation group and 19 to the three other groups.

\section{Results}

A one-way ANOVA with the factor group revealed that different habituation yielded different performance $[F(3,71)=3.68, p=.016]$. A comparison of means showed that only the English group differed significantly from the others. Planned $t$ tests comparing the Dutch with the French and English groups revealed only marginally significant effects $[F(1,35)=2.77, p=.10$ (twotailed), for Dutch vs. French, and $F(1,36)=2.12, p=$ .15 , for Dutch vs. English].

\section{Discussion}

This experiment confirms the finding of Experiment 3: Listening to compressed French does not help to process compressed English. On the other hand, the subjects habituated to compressed Dutch displayed an improvement in performance that is half the one yielded by English. The effect is small, and the differences not quite statistically significant (although, with a one-tailed hypothesis,

Table 4

Mean Percent Recalled Syllables (With Standard Error) From Compressed English Sentences for Monolingual English Subjects Trained With Different Languages

\begin{tabular}{lcc}
\hline & \multicolumn{2}{c}{ English Sentences } \\
\cline { 2 - 3 } Habituation & $M$ & $S E$ \\
\hline None & 52.1 & 3.7 \\
English & 65.2 & 3.7 \\
French & 50.3 & 3.5 \\
Dutch & 58.1 & 3.1 \\
\hline
\end{tabular}

the French vs. Dutch comparison has $p=.05$ ). Unfortunately, it was impossible for us to test more subjects, which might have given us stronger results. Nonetheless, this experiment has served to confirm previous observations and has uncovered a trend that upholds our hypothesis that adaptation is a function of the similarity between languages at the prelexical level.

\section{GENERAL DISCUSSION}

The results reported for these four experiments show that comprehension of compressed speech can improve when subjects are exposed to compressed sentences in other languages; yet not every language will help. Habituation to either Spanish or Catalan improves comprehension of sentences in the other language. In contrast, prior habituation to French does not improve comprehension of English, nor does exposure to English help comprehension of French. Habituation to Dutch tends to facilitate the processing of English. One could prima facie hypothesize that this effect would require the subjects' comprehension of the habituation language. In fact, Spanish and Catalan have a greater lexical overlap than do English and French or English and Dutch.

Our experiments, however, suggest that, when crosslinguistic adaptation to compressed speech is observed, it remains robust, regardless of whether subjects understand the habituation sentences or not. Indeed, although bilingual speakers of Spanish and Catalan improve their performances on the test sentences when they are habituated to the other language, monolingual speakers of Spanish who do not understand Catalan improve as much as the bilinguals do. A similar trend of improvement was observed for English speakers exposed to compressed Dutch, a language that they do not understand. Conversely, bilingual speakers of French and English, who do understand both languages, nevertheless fail to show adaptation from one language to the other. Therefore, without denying that comprehension may augment adaptation, we have to invoke some other properties to explain why it is that the recollection of compressed sentences is enhanced from prior exposure to certain other languages, regardless of whether the subjects understand them or not.

The finding that adaptation to compressed speech arises without comprehension is compatible with the study by Altmann and Young (1993), which showed that subjects exhibit a significant improvement in the processing of compressed sentences after listening to sentences composed of nonwords. Moreover, the finding that adaptation to compressed speech shows transfer for some language pairs and not for others suggests that low-level tuning to acoustic properties of fast speech might not be crucial. Again, this is compatible with the study by Dupoux and Green (1997) showing transfer of adaptation when different speakers utter the habituation and test sentences (replicated in our Experiments 1, 2, and 4). What we are looking for, then, is a set of properties, more abstract than acoustics, that are language specific but that do not re- 
quire comprehension. Such properties as these can, of course, be found at the level of phonology. In fact, a growing body of data suggests that speech perception involves a processing level that encodes the phonological properties of linguistic sounds in a language-specific way (Otake \& Cutler, 1996; Otake et al., 1993). This processing level, which has been called prelexical, would mediate between the lexical level and the acoustic/phonetic level. Cutler et al. $(1983,1986)$ have argued that French and English depend on contrasting prelexical representations. These differences in the prelexical representations generate different behaviors in a fragment detection task. In related studies, Sebastian-Gallés et al. (1992) have shown that Spanish and Catalan subjects behave in a fragment detection task as if they used similar prelexical representations for both languages. In other experiments, Otake et al. (1993) show that speakers of Japanese have prelexical representations that are different from those used for any of the above-mentioned Indo-European languages.

The observed adjustments to compressed speech are consistent with the data from many studies on the role of prelexical properties on processing. Indeed, different languages use more or less similar prelexical representations. Why is it that Spanish and Catalan show reciprocal adjustments? This occurs because both languages rely on syllables and on an accent that falls, roughly, in the penultimate syllable of open class words. Although subjects may or may not understand the compressed sentences, they exploit these regularities in the signal. When they switch to the test sentences, these adjustments prove to be useful. Likewise, why is it that French and English do not show such reciprocal adjustments? This failure occurs because French relies on syllables and on an accent that always appears in the last syllable of every open class word, whereas English does not show an equal reliance on syllables but instead highlights strong as opposed to weak syllables in its prelexical representations (Cutler \& Norris, 1988).

The experiments reported suggest that the study of adaptation to compressed speech may help us to classify languages in terms of their sound patterns. In a manner that is similar to that in which phonemes can be organized into a matrix of features that can predict perceptual confusions (G. A. Miller \& Nicely, 1955), natural languages may fit into natural classes that can be equally organized into a similarity space. Future studies will show whether this is the case.

\section{REFERENCES}

ABERCROMBIE, D. (1967). Elements of general phonetics. Chicago: Aldine.

Altmann, G. T. M., \& Young, D. H. (1993, September). Factors affecting adaptation to time-compressed speech. Paper presented at Eurospeech 9, Berlin.

Bradley, D. C., Sánchez-Casas, R. M., \& García-Albea, J. E. (1993). The status of the syllable in the perception of Spanish and English. Language \& Cognitive Processes, 8, 197-233.

Charpentier, F. J., \& Stella, M. G. (1986, April). Diphone synthesis using an overlap-add technique for speech waveforms concatenation. Paper presented at the IEEE International Conference ASSP, Tokyo.
Cutler, A., Merler, J., Norris, D., \& Segui, J. (1983). A language specific comprehension strategy. Nature, 304, 159-160.

Cutler, A., Mehler, J., Norris, D., \& Segui, J. (1986). The syllable's differing role in the segmentation of French and English. Journal of Memory \& Language, 25, 385-400.

Cutler, A., Mehler, J., Norris, D. G., \& Segui, J. (1992). The monolingual nature of speech segmentation by bilinguals. Cognitive Psychology, 24, 381-410.

CUtLer, A., \& NorRIS, D. (1988). The role of strong syllables in segmentation for lexical access. Journal of Experimental Psychology: Human Perception \& Performance, 14, 113-121.

DE HAAN, H. J. (1982). The relationship of estimated comprehensibility to the rate of connected speech. Perception \& Psychophysics, 32, 27-31.

Dupoux, E., \& GREeN, K. (1997). Perceptual adjustment to highly compressed speech: Effects of talker and rate changes. Journal of Experimental Psychology: Human Perception \& Performance, 23, 914-927.

FoulKE, E., \& STICHT, T. (1969). Review of research on the intelligibility and comprehension of accelerated speech. Psychological Bulletin, 72, 50-62.

Heiman, G. W., Leo, R. J., Leighbody, G., \& Bowler, K. (1986). Word intelligibility decrements and the comprehension of time-compressed speech. Perception \& Psychophysics, 40, 407-411.

Mehler, J., Dommergues, J. Y., Frauenfelder, U., \& Segui, J. (1981). The syllable's role in speech segmentation. Journal of Verbal Learning \& Verbal Behavior, 20, 298-305.

Mehler, J., Sebastian-Gallés, N., Altmann, G., Dupoux, E., Christophe, A., \& Pallier, C. (1993). Understanding compressed sentences: The role of thythm and meaning. In P. Tallal, R. R. Llinás, \& C. von Euler (Eds.), Temporal information processing in the nervous system: Special reference to dyslexia and dysphasia (Annals of the New York Academy of Sciences, Vol. 682, pp. 272-282). New York: New York Academy of Sciences.

MilLeR, G. A., \& NiCELY, P. E. (1955). An analysis of perceptual confusions among some English consonants. Journal of the Acoustical Society of America, 27, 338-352.

MiLLER, J. L. (1981). Effects of speaking rate on segmental distinctions. In P. D. Eimas \& J. L. Miller (Eds.), Perspectives on the study of speech. Hillsdale, NJ: Erlbaum.

OTAKE, T., \& CUTLER, A. (EDs.) (1996). Phonological structure and language processing. Berlin: Mouton de Gruyter.

Otake, T., Hatano, G., Cutler, A., \& Mehler, J. (1993). Mora or syllable? Speech segmentation in Japanese. Journal of Memory \& Language, 32, 258-278.

Pallier, C., Sebastian-Gallés, N., Felguera, T., Christophe, A., \& MEHLER, J. (1993). Attentional allocation within the syllabic structure of spoken words. Journal of Memory \& Language, 32, 373-389.

SCHMitT, J. G., MoORE, S. W., \& LASs, N. J. (1986). Variable speech control vs. Varispeech: Does newer mean better? Journal of Auditory Research, 26, 183-190.

Schwab, E. C., Nusbaum, H. C., \& Pisoni, D. B. (1985). Some effects of training on the perception of synthetic speech. Human Factors, 27 , 395-408.

Sebastian-Gallés, N., Dupoux, E., Segui, J., \& Mehler, J. (1992). Contrasting syllabic effects in Catalan and Spanish. Journal of Memory \& Language, 31, 18-32.

Voor, J. B., \& Miller, J. M. (1965). The effect of practice on the comprehension of worded speech. Speech Monographs, 32, 452-455.

ZWITSERLoOd, P., Schriefers, H., Lahiri, A., \& DonselaAr, W. V. (1993). The role of the syllable in the perception of spoken Dutch. Journal of Experimental Psychology: Learning, Memory, \& Cognition, 19, 260-271.

\section{APPENDIX \\ Materials for Experiments}

\section{Experiments 1 and 2}

Test Sentences in Spanish

Le dije que volviera antes del mes de julio.

Cerró la puerta poco a poco para no despertar a su hija.

Esta silla es mucho más cómoda que la otra. 
Estas atletas han sido las ganadoras de la última carrera. Empezó a pintar hace tres meses.

\section{Test Sentences in Catalan}

$\mathrm{Li}$ vaig dir que tornes abans del mes de juliol.

Va tancar la porta poc a poc per a no despertar la seva filla.

Aquesta cadira es molt mes comoda que l'altre.

Aquestes atletes han estat les guanyadores de la darrera cursa.

Va començar a pintar fa tres mesos.

\section{Experiment 3}

Test Sentences in English

The group of comedians has staged a parody of the parliament.

The apartments in this building are too noisy for my parents.

The policeman chased the burglar on the roof of the bank.

The group of players that comes is surely the most important.

The young doctor has said that both your arms are broken.

The long pathway that leads to the sea is really pretty.

The dog is an animal that is in general always adorable.

The discussion is always centred on the problems of the economy.

He takes the bus to accompany his wife to the dentist.

My grandparents were born only two years before the great war.

The young girl sleeps in the old hotel near the park.

The old man has a certain experience of these good wines.

The music on the radio is too modern for my cousin.

The product invented by this little man is toxic and lethal.

Each morning the young priest reads ten pages of the bible.

The minister has a great interest for all the new projects.

\section{Test Sentences in French}

La troupe de comédiens a joué une parodie sur les députés.

Les appartements dans cet immeuble sont trop bruyants pour mes parents.

Le policier poursuit le voleur sur le toit de la banque.

Le groupe de joueurs qui vient est sûrement le plus important. Le jeune docteur a dit que tes deux bras sont cassés.

Le long chemin qui mène à la mer est vraiment joli.

Le chien est un animal qui est en général toujours adorable.

La discussion est toujours centrée sur les problèmes de la sécurité.

Il prend le bus pour accompagner sa femme chez le dentiste.

Mes grandparents sont nés presque deux ans avant la grande guerre.

La jeune fille dort dans le vieil hotel près du parc.

Le vieil homme a une certaine habitude de ces bons vins.

La musique à la radio est trop moderne pour ma cousine.

Le produit inventé par ce petit homme est toxique et mortel.

Chaque matin, le jeune prêtre lit dix pages de la bible.

Le ministre a un grand intérêt pour tous les nouveaux projets.

\section{Experiment 4}

Having a big car is not something I would recommend in this city.

Trade unions have lost a lot of their influence during the past ten years.

The library is opened every day from 8 am to $6 \mathrm{pm}$.

They didn't hear the good news until last week on the visit to their friends.

The government is planning a reform of the education programme. 